\title{
How depression and sleep quality are associated with state-trait anxiety in medical school undergraduates in Anhui Province, China: A mediation analysis
}

\author{
Jiangyun Chen \\ Management of Southern Medical University \\ Yusupujiang Tuersun \\ Management of Southern Medical University \\ Jiao Yang \\ Management of Southern Medical University \\ Man Xiong \\ Management of Southern Medical University \\ Yueying Wang \\ Management of Southern Medical University

\section{Xinyi Rao} \\ Management of Southern Medical University \\ Shuai Jiang ( $\square$ shuaij@126.com ) \\ The First Affiliated Hospital of Zhengzhou University
}

\section{Research Article}

Keywords: adolescents, medical students, sleep quality, depression, state-trait anxiety, Chinese

Posted Date: March 3rd, 2022

DOl: https://doi.org/10.21203/rs.3.rs-1350270/v2

License: (c) (1) This work is licensed under a Creative Commons Attribution 4.0 International License. Read Full License 


\section{Abstract}

Background: To investigate the relationship between depression and sleep quality and state-trait anxiety among undergraduate students in medical colleges and universities in Anhui Province, to enhance the attention to the mental health of undergraduate students in medical colleges and universities, and to provide a basis for mental health intervention strategies for undergraduate students in medical colleges and universities.

Methods: The Pittsburgh Sleep Quality Index, State-Trait Anxiety Inventory, and Depression Self-Rating Scale were used to investigate 1300 college students in four medical undergraduate colleges and universities in Anhui Province.

Results: The Pittsburgh Sleep Quality Index score was (5.87+2.944), the State-Trait Anxiety Inventory score was (84.10+17.276), and the Depression Self-Rating Scale score was (49.04+10.845). Depression status and Pittsburgh Sleep Quality Index were positively correlated $(r=0.381, p<0.001)$, and Pittsburgh Sleep Quality Index and State-Trait Anxiety were positively correlated $(r=0.428, p<0.001)$.

Conclusions: Taking four undergraduate medical colleges and universities in Anhui Province as an example, sleep quality of college students in medical colleges and universities was positively correlated with depressive state, sleep quality and state-trait anxiety were positively correlated, and sleep quality was influencing depressive state through state-trait anxiety.

\section{Background}

According to the updated data of the World Health Organization in 2017, 264 million people of all ages worldwide suffer from depression, among which the lifetime prevalence of depression in China is $6.9 \%$, and the proportion of Chinese university students suffering from depression is as high as $23.66 \%$. As a social group with high intelligence and pursuit, college students are the leading force to support the development and progress of society, and only with healthy and qualified physical and psychological quality can they take up all the important responsibilities in the future. The competition in contemporary society is getting fierce, the number of college graduates is increasing year by year, and the employment and life pressure of college students are high, so the mental health of college students deserves attention and attention. Many scholars in psychology, medicine, and education in China have researched the mental health status of college students. The survey results of Du Zhaoyun and Wang Keqin on 1579 college students show that the prevalence of mild depression is $42.1 \%$ and the prevalence of severe depression is $2.1 \%$.[1].According to statistics, the mental health problems of college students in China have been rising, with $28.23 \%$ of college students having mental disorders in the 1990 s and $42 \%$ in recent years. According to the Ministry of Health, the mental health problems of modern college students are manifested as depression and anxiety, etc.[2].

Medical school students are the training base for future medical workers and health administrators, so paying attention to the physical and mental health of medical school students has become the top 
priority for paying attention to the mental health of college students, which is the cornerstone of the future development of medical and health care.

Sleep is vital to human health[3], however, many people still suffer from sleep disorders, and many diseases are associated with poor sleep, such as cancer[4, 5], Heart Failure[6, 7], Depression, and general anxiety disorders[8], Schizophrenia, etc.[9].For many college students, the transition to high school brings many new challenges, such as academic stress, smoking and drinking, physical activity, living environment, physical status, psychological status, work obligations, and new independence, which may provide the necessary stress for the development or worsening of sleep disorders, thus making sleep problems common among college students[10], More than half of college students suffer from poor sleep quality, which is more severe than the general population (according to statistics updated by the World Health Organization in 2017) and is detrimental to physical and mental health. Therefore, it can be asserted that poor sleep quality is becoming a considerable problem among university students.

Sleep disorders refer to abnormalities in the quantity or quality of sleep, or some clinical symptoms that occur during sleep[11]. Insomnia is the most common sleep disorder in patients with depression, and this sleep disorder is considered an asymptomatic dimension of current depression. Sleep disturbance often lingers, and its persistence may represent a residual phase of the primary mood disorder. Alternatively, the presence of a sleep disorder may be a precursor or harbinger of depression that occurs later in life. Indeed, as part of an epidemiological catchment area study[12], Ford and Kamerow[13]discover, persistent insomnia is associated with the development of the new major depressive disorder. Clinical and epidemiological investigations have shown that sleep disorders are closely associated with depression, highlighting the co-morbidity of sleep disorders and depression, including the concurrent comorbidity model and the sequential co-morbidity model[14].In addition, it has been shown that as the level of depression increases, the total sleep quality and sleep quality component scores increase significantly, and on the other hand, depression levels are significantly higher in people with poor sleep quality than in people with good sleep quality[15]. Changes in sleep architecture, such as those found in restricted sleep may also impair physiological function and increase depressive symptoms. In addition, research suggests that sleep, as an anti-inflammatory mechanism, may help maintain physical function later in life[16]. Sleep disorders are common in college student populations, although the prevalence appears to be variable, perhaps in part due to methodological differences. Nardoff[17]In a sample of 583 students, $13 \%$ reported clinically significant insomnia symptoms (according to the Insomnia Severity Index [ISI]) in the past 2 weeks. Gaultney[18]discover, in a large sample of college students $(N=1,845)$, $27 \%(n=500)$ were at risk for sleep disorders (using the SLEEP-50, a tool validated for college students that measures sleep characteristics)[19]). Other studies have reported a greater prevalence of sleep disorders. In one large study $(\mathrm{N}=1,125)$, the Pittsburgh Sleep Quality Index (PSQI) classified more than $60 \%$ of college students as poor sleepers[20]. Finally, Singleton[21]discover, Of the 236 students who completed the interview survey, $79 \%$ reported going to bed after midnight, and only $24 \%$ reported getting enough sleep at night (i.e., at least 8.4 hours). In addition, there may be a cohort effect in that an even higher percentage of college students in recent generations self-reported dissatisfaction with their sleep. 
Depression and anxiety disorders are among the most common disorders in the community and primary care. People with depression often have features of anxiety disorders, and people with anxiety disorders usually have depression as well. Both disorders may occur together and meet the criteria for both disorders, with approximately $85 \%$ of people with depression having significant anxiety and $90 \%$ of people with anxiety having depression[22].In the STAR*D study, $45 \%-46 \%$ of the 3787 outpatients with depression were considered to meet the criteria for anxiety depression[19]. Näslund [23], illustrates the close relationship between anxiety and depression.

Anxiety and state-trait worry (WT) are closely related, but they are separate psychological concepts. Clinical studies have shown that high WT, especially high pathological worry, is an important clinical feature of anxiety disorders[24].Åkerstedt et al. (2007) found that people with higher levels of pre-bedtime WT were significantly less efficient sleepers compared to those with lower levels; people with higher levels of worry took longer to fall asleep and exhibited longer periods of light sleep. In addition, researchers noted that worry has been shown to differ from rumination in terms of its effect on sleep quality. The effect of state-trait worry on sleep quality is that it focuses on ongoing or future uncertain events, whereas rumination further exacerbates existing sleep problems by focusing on the "why", i.e., the cause of the problem, and people look back to the past to find an explanation[25]. Anxiety includes state anxiety (S-Al), a description of momentary, fluctuating states of emotional feeling, and trait anxiety (T-Al), a tendency toward sustained, relatively stable trait anxiety. Frequent anxiety, in turn, consolidates anxiety traits, and individuals with higher levels of T-Al show more S-Al. In addition, individuals with high T-Al show evidence of attentional bias. They tend to pay attention to and even exaggerate negative emotional information, which directly correlates with their sleep quality[26]. Christopher et al [27] argued that T-Al not only directly elicits high anxiety states but also modulates anxiety arousal by affecting the preattentive system, thus causing attentional bias. Among other things, T-Al plays an important role in evoking emotional arousal; the higher the T-Al of an individual, the more easily negative emotions are aroused and the poorer the quality of sleep.

Because the modern biomedical paradigm has not been transformed thoroughly enough, the singularity of education that focuses only on medical students' professional knowledge and not on the development of psychological and social knowledge is more serious; therefore, current research on the mental health of medical students is limited, with some focusing on the relationship between apprehension tendencies and sleep quality and the mediating role of state-anxiety[28]. So far no study has analyzed one relationship between PSQI, STAI, and SDS. Therefore, the present study focused on the mediating role of traits between sleep and depression. Based on the purpose of our study, we made the following hypotheses.

1 , there is a link between sleep disturbance and depression

2. state traits moderate the relationship between sleep disturbance and depression in college students

\section{Methods}




\section{Sampling Method}

From September to December 2020, convenience sampling method was used to select college students of Anhui Medical University, Anhui University of Traditional Chinese Medicine, Bengbu Medical College, and Wannan Medical College, four medical universities as the survey subjects. The questionnaires were filled out anonymously online, and a total of 1300 questionnaires were collected, with 1277 valid questionnaires (594 males and 633 females) and an effective rate of $98.23 \%$. The study followed the principle of voluntary participation, and all respondents signed an informed consent form.

\section{Procedures}

\section{Quality of sleep (PSQI)}

Sleep quality was assessed using the Pittsburgh Sleep Quality Index[29]. The index consists of 19 selfrated items that are combined to provide a score of 7 on a scale from 0 to 3 , where 0 indicates no difficulty and 3 indicates severe difficulty. The scores of these seven components are combined to provide a total score of $0-21$, with higher scores indicating poorer sleep quality, and scores greater than 5 distinguishing poor sleepers from good sleepers. the PSQI is considered an appropriate tool for assessing sleep quality in adults (18-80 years)[30], Cronbach's alpha among adolescents and young adults was 0.72[31]. The PSQI scale in this study was divided into two levels of presence or absence of sleep disorder ( 1 = with sleep disorder, 2 = without sleep disorder) and four levels of degree of sleep quality ( $1=$ fair sleep quality, 2 = fair sleep quality, 3 = very poor sleep quality, 4 = very good sleep quality) by the scores of the collected data.

\section{State-Trait Anxiety Inventory (STAI)}

The STAI questionnaire consists of 40 questions divided into two groups to assess anxiety as a transient state (state anxiety) and as an underlying trait (trait anxiety). State anxiety is considered to be a transient emotional state characterized by subjective feelings, apprehension, and overactivity of the autonomic nervous system. Trait anxiety is a relatively stable personal state with a tendency to perceive situations as threatening. Both the state and trait scales consist of 20 items, including directly and inversely worded questions and punctuation. Scores range from 20 to 80 , with higher scores indicating higher levels of anxiety[32, 33]. The final STAI scores were obtained using an online calculator (https://www.nsrusa.org/score.php) to avoid confusion about the punctuation of the reverse wording.

\section{Depression Self-Rating Scale (SDS)}

The SDS is a brief self-rating scale that assesses the psychological and somatic symptoms of depression. It has been widely used in different age groups for screening purposes and to measure 
depression[34]. It has been widely used to screen for and measure the severity of depression[35]. It has good internal consistency [36] test and retest reliability and has good content validity and criterion validity[36]. The SDS consists of 20 items and is designed based on diagnostic criteria for depression. Subjects rated how each item felt over the past few days using a 4-point Likert scale. raw sum scores for the SDS range from 20 to 80 , but results are usually displayed as an SDS index, which is obtained by expressing raw scores converted to a 100 -point scale.

\section{Covariates}

Age and gender were included as fixed covariates in the adjustment. Other covariates were included in the final model as potential confounders if they altered PSQI/STAI estimates of SDS class levels by $>10 \%$ or were significantly associated with SDS class levels. The following covariates were selected and tested based on the identified associations and/or plausible biological relationships. Respondent's profession, whether he/she was an only child, place of birth, closest relationship, closest person's education level, father's education level, mother's education level, closest person's job, father's job, mother's job, and ethnicity. The relationship between each confounding factor and SDS is detailed in Supplementary Tables 1, 2, and 3.

\section{Statistical analysis}

Two-by-two correlation analysis was performed between variables using a bias-off. Means (standard deviations, SD) and proportions were used to characterize participants. Multiple linear regression was used to assess the relationship between PSQI, STAI, and SDS.

Regression models were used to estimate the relationship between PSQI, STAI, and SDS. Relative beta and $95 \%$ confidence intervals $(\mathrm{Cl})$ were calculated.

All models and bias correlations were conducted after adjusting for age, gender, respondent's profession, being an only child, place of birth, closest relationship, closest person's education level, father's education level, mother's education level, closest person's job, father's job, mother's job, and ethnicity.

We analyzed the mediating effect of STAI on the association between PSQI and SDS by Sobel-Goodman mediation test, with all selected covariates controlled. Each model included six equations.[37]. The Sobel test was used to test the hypothesis that the indirect effect is equal to zero[38]. Point estimates and 95\% confidence intervals were estimated for the indirect effects. Full mediation holds when the independent variable (PSQI) and the dependent variable (SDS) are uncorrelated after controlling for the mediator (STAI) so that the path Eq. 3 ' is zero. Partial mediation occurs when the absolute size of the path from PSQI to SDS decreases but remains different from zero after the introduction of the mediator. The percentage of mediation is calculated as 1 -(Eq. $3^{\prime} /$ Eq. 3), where Eq. 3 is the role of the independent variable in predicting the main outcome and Eq. 3 ' is the role of the independent variable in predicting the dependent and mediating variables. 
P-values were 2-sided and an alpha level of 0.05 was used to define statistical significance. Data were analyzed using SPSS 26.0 (IBM Corporation), Stata (version 15), and R version 3.6.3 (R Foundation for Statistical Computing, Vienna, Austria).

\section{Results}

\section{General characteristics}

$74.33 \%$ (912) of the respondents reported having sleep disorders and $41.40 \%$ (518) reported suffering from depression, of which mild, moderate and severe were:26.65\% (327), 13.94\% (171), and $0.81 \%$ (10) respectively. With sleep disorders were:27.27\% (162), $24.17 \%$ (153), men and women who reported having depression were:41.58\% (247), 41.23\% (261), respectively; with mild depression were:26.94\% (160), 26.38 (167); moderate depression were:13.64\% (81), respectively $14.22 \%$ (90); and major depression were: $1.01 \%$ (6) and $0.63 \%$ (4), respectively. Interestingly, there was no statistically significant difference in the gender distribution of the incidence of sleep disorders and depression. (Table 1) 
Table 1

Characteristics of Respondents $(\mathrm{N}=1227)$

\begin{tabular}{|c|c|c|c|}
\hline & Overall $(n=1227$ & Men $(n=594)$ & $\begin{array}{l}\text { Women }(n= \\
633)\end{array}$ \\
\hline Grade & $\mathrm{N}(\%)$ & & \\
\hline 1 & $288(23.47 \%)$ & $121(20.3 \%)$ & $167(26.38 \%)$ \\
\hline 2 & $75(6.11 \%)$ & $39(6.57 \%)$ & $36(5.69 \%)$ \\
\hline 3 & $91(7.42 \%)$ & $43(7.24 \%)$ & $48(7.58 \%)$ \\
\hline 4 & $676(55.09 \%)$ & $345(58.0 \%)$ & $331(52.29 \%)$ \\
\hline 5 & $97(7.91 \%)$ & $46(7.74 \%)$ & $51(8.06 \%)$ \\
\hline \multicolumn{4}{|l|}{ Major } \\
\hline Medicine & 1087(88.59\%) & $520(87.5 \%)$ & $567(89.57 \%)$ \\
\hline Other & $140(11.41 \%)$ & $74(12.46 \%)$ & $66(10.43 \%)$ \\
\hline \multicolumn{4}{|l|}{ Race } \\
\hline Han & 1193(97.23\%) & $578(97.31 \%)$ & $615(97.16 \%)$ \\
\hline Minority & $24(1.96 \%)$ & $16(2.69 \%)$ & $18(2.84 \%)$ \\
\hline \multicolumn{4}{|l|}{ Only child } \\
\hline No & $740(60.31 \%)$ & $314(52.86 \%)$ & $426(67.30 \%)$ \\
\hline Yes & $487(36.69 \%)$ & $280(47.14 \%)$ & $207(32.70 \%)$ \\
\hline \multicolumn{4}{|l|}{ Birthplace } \\
\hline Urban & $432(35.21 \%)$ & 199(33.50\%) & $233(36.81 \%)$ \\
\hline Rural & $795(64.79 \%)$ & $395(66.50 \%)$ & $400(63.19 \%)$ \\
\hline \multicolumn{4}{|l|}{ Closet relationship } \\
\hline Parents & 1006(81.99\%) & 492(82.83\%) & $514(81.20 \%)$ \\
\hline Grandparents & $145(11.82 \%)$ & $60(10.10 \%)$ & $85(13.43 \%)$ \\
\hline Siblings & $51(4.16 \%)$ & $27(4.55 \%)$ & $24(3.79 \%)$ \\
\hline Other & $25(2.04 \%)$ & $15(2.53 \%)$ & $10(1.58 \%)$ \\
\hline \multicolumn{4}{|l|}{ Education of closest relationship } \\
\hline Less than lower secondary education & $640(52.16 \%)$ & $301(50.6 \%)$ & $339(53.5 \%)$ \\
\hline Upper secondary \& vocational & $251(20.46 \%)$ & $148(24.92 \%)$ & $103(16.27 \%)$ \\
\hline
\end{tabular}




\begin{tabular}{|c|c|c|c|}
\hline & Overall $(n=1227$ & Men $(n=594)$ & $\begin{array}{l}\text { Women }(n= \\
633)\end{array}$ \\
\hline Tertiary education & $336(27.38 \%)$ & $145(24.41 \%)$ & $191(30.17 \%)$ \\
\hline \multicolumn{4}{|l|}{ Education of father } \\
\hline Less than lower secondary education & $662(53.95 \%)$ & $313(52.69 \%)$ & $349(55.13 \%)$ \\
\hline Upper secondary \& vocational & $290(23.63 \%)$ & $157(26.43 \%)$ & $133(21.10 \%)$ \\
\hline Tertiary education & $275(22.41 \%)$ & $124(20.88 \%)$ & $151(23.85 \%)$ \\
\hline \multicolumn{4}{|l|}{ Education of mother } \\
\hline Less than lower secondary education & $820(66.83 \%)$ & $386(64.98 \%)$ & $434(68.56 \%)$ \\
\hline Upper secondary \& vocational & $235(19.15 \%)$ & $136(22.90 \%)$ & $99(15.64 \%)$ \\
\hline Tertiary education & $172(14.02 \%)$ & $72(12.12 \%)$ & $100(15.80 \%)$ \\
\hline \multicolumn{4}{|l|}{ Job of closest relationship } \\
\hline Workers & $396(32.27 \%)$ & $226(38.05 \%)$ & $170(26.86 \%)$ \\
\hline Farmers & $206(16.79 \%)$ & $94(15.82 \%)$ & $112(17.69 \%)$ \\
\hline $\begin{array}{l}\text { Civil servants, teachers and other } \\
\text { intellectuals }\end{array}$ & $264(21.52 \%)$ & $110(18.52 \%)$ & $154(24.33 \%)$ \\
\hline Businessmen & $172(14.02 \%)$ & $82(13.80 \%)$ & $90(14.22 \%)$ \\
\hline Others & 199(16.22\%) & $82(13.80 \%)$ & $107(16.90 \%)$ \\
\hline \multicolumn{4}{|l|}{ Job of father } \\
\hline Workers & $534(43.52 \%)$ & $275(46.30 \%)$ & $259(40.92 \%)$ \\
\hline Farmers & 131(10.68\%) & $64(10.77 \%)$ & $67(10.58 \%)$ \\
\hline $\begin{array}{l}\text { Civil servants, teachers and other } \\
\text { intellectuals }\end{array}$ & 237(19.32\%) & 108(18.18\%) & $129(20.38 \%)$ \\
\hline Businessmen & 197(16.06\%) & $94(15.82 \%)$ & $103(16.27 \%)$ \\
\hline Others & 128(10.43\%) & $53(8.92 \%)$ & $75(11.85 \%)$ \\
\hline \multicolumn{4}{|l|}{ Job of mother } \\
\hline Workers & $431(35.13 \%)$ & $239(40.24 \%)$ & 192(30.33\%) \\
\hline Farmers & $243(19.80 \%)$ & 112(18.86\%) & $131(20.70 \%)$ \\
\hline $\begin{array}{l}\text { Civil servants, teachers and other } \\
\text { intellectuals }\end{array}$ & $185(15.08 \%)$ & $86(14.48 \%)$ & $99(15.64 \%)$ \\
\hline Businessmen & 154(12.55\%) & $72(12.12 \%)$ & $82(12.95 \%)$ \\
\hline
\end{tabular}




\begin{tabular}{|llll}
\hline & Overall $(\boldsymbol{n}=\mathbf{1 2 2 7}$ & Men $(\boldsymbol{n}=\mathbf{5 9 4})$ & $\begin{array}{l}\text { Women }(\boldsymbol{n}= \\
\mathbf{6 3 3})\end{array}$ \\
\hline Others & $214(17.44 \%)$ & $85(14.31 \%)$ & $129(20.38 \%)$ \\
\hline STAI(Mean + SD) & $84.10+17.276$ & $\begin{array}{l}84.23+ \\
17.759\end{array}$ & $83.98+16.822$ \\
& & $5.75+3.040$ & $5.97+2.850$ \\
\hline PSQI(Mean + SD) & $5.87+2.944$ & $\begin{array}{l}48.87+ \\
11.087\end{array}$ & $49.19+10.619$ \\
\hline SDS(Mean + SD) & $49.04+10.845$ & & \\
\hline
\end{tabular}

\section{Correlation Analysis}

SDS was positively correlated with PSQI $(r=0.381, p<0.001)$, with STAI $(r=0.428, p<0.001)$, and PSQI with STAI $(r=0.428, p<0.001)$ when controlling for confounding factors. (Table 2$)$

Table 2

Partial Correlations Coefficients (r) among STAl, PSQI, and SDS.

\begin{tabular}{|c|c|c|c|}
\hline & STAI & PSQI & SDS \\
\hline \multicolumn{4}{|l|}{ STAI } \\
\hline PSQI & $0.428 * \star \star *$ & & \\
\hline SDS & $0.775^{\star \star \star}$ & $0.381^{* \star *}$ & \\
\hline
\end{tabular}

Values are bolded if they achieved statistical significance at $p \leq .05$.

$\star p \rrbracket 0.05, * \star p \rrbracket 0.01, * \star \star p \rrbracket 0.001$.

Abbreviations: STAI = State-Trait Anxiety Inventory; PSQI = Pittsburgh Sleep Quality Index; SDS = Selfrating depression scale.

\section{Mediation Analysis}

The results of the mediation analysis were as follows: overall, sleep quality scores were positively correlated with depression scores. State-trait anxiety mediation analysis revealed that the association between sleep quality and depression scores was mediated by state-trait anxiety. The adjusted role of mediation for potential confounders was about $83.79 \%$. More precisely, the effect of state-trait anxiety on sleep quality was $83.79 \%(z=15.090)$ when the dependent variable was depression score. Thus, it is clear 
that state-trait anxiety plays a fully mediating role in analyzing the effect of sleep quality on depressive states. That is, sleep quality is influenced by depressive states through state-trait anxiety. (Figure 1)

\section{Subgroup analysis}

In this study, subgroup analyses were conducted separately for gender and place of birth of the surveyed respondents, and the results of the subgroup analysis of the STAI-mediated mediation model related to SDS and PSQI were found to be inconsistent with the results of our study hypothesis for this group of participating males and the group born in urban areas. (Table3)

Table 3

Subgroup analysis of mediation models for SDS associated with PSQI mediated by STAI in Medical School Students.

\begin{tabular}{|lllllll|}
\hline & $\begin{array}{l}\text { Indirect } \\
\text { effect }\end{array}$ & $\begin{array}{l}\text { Direct } \\
\text { effect }\end{array}$ & $\begin{array}{l}\text { Total } \\
\text { effect }\end{array}$ & $\mathbf{Z}$ & $\begin{array}{l}\text { Sobel } \boldsymbol{p} \\
\text { value }\end{array}$ & $\begin{array}{l}\text { Proportion of total effect that } \\
\text { is mediated }\end{array}$ \\
\hline Gender & & & & & & \\
\hline Male & $1.217^{\star \star \star}$ & 0.149 & $1.366^{\star \star \star}$ & 10.88 & 0.000 & $89.12 \%$ \\
\hline Female & $1.117^{\star \star \star}$ & $0.315^{\star \star}$ & $1.432^{\star \star \star}$ & 10.31 & 0.000 & $78.01 \%$ \\
\hline Birthplace & & & & & & \\
\hline Urban & $1.104^{\star \star \star}$ & 0.189 & $1.294^{\star \star \star}$ & 8.411 & 0.000 & $85.37 \%$ \\
\hline Rural & $1.213^{\star \star \star}$ & $0.247^{\star \star}$ & $1.461^{\star \star \star}$ & 12.52 & 0.000 & $83.07 \%$ \\
\hline
\end{tabular}

Note: STAI = State-Trait Anxiety Inventory; PSQI = Pittsburgh Sleep Quality Index; SDS = Self-rating depression scale. Sobel-Goodman Mediation Test in adjusted models for gander, birthplace, grade, major, race, only child, close relationship, education of close relationship, education of father, education of mother, job of close relationship, job of father, job of mother. Values are bolded if they achieved statistical significance at $p \leq .05 . * p \rrbracket 0.05, * \star p \rrbracket 0.01, * \star \star p \rrbracket 0.001$

\section{Discussion}

Based on controlling for covariates, partial correlation analysis revealed a two-by-two correlation between STAI, PSQI, and SDS. Sleep disorders disrupt human biological functions, altering brain electrical stimulation and having an impact on individual emotional perceptions, thus affecting psychological states and even triggering depression[39]. Thus people with poor sleep quality are more likely to experience depressive symptoms, state, and trait anxiety. Sleep deprivation leads to a significant increase in state anxiety levels[40], Anxiety can also lead to impaired sleep initiation and reduced rapid eye movement and slow-wave sleep[41]. Other studies have also found a bidirectional relationship between sleep disorders and depression, with major depression being associated with hypersomnolence, and depression leading to sleepiness symptoms such as prolonged nighttime sleep and impaired quality of wakefulness[42]. Sleep disorders, especially nightmares and insomnia, can also exacerbate suicidal behavior in people with depression[43], Therefore, it is of great practical importance to pay attention to 
the relationship between sleep disorders and depressive states trait anxiety, so that we can take appropriate measures to improve the sleep quality of college students and thus reduce depression and anxiety, and promote the physical and mental health of college students.

Depression and anxiety disorders are among the most common disorders in the community and primary care. People with depression often have features of anxiety disorders, while people with anxiety disorders usually also have depression. The two disorders may occur together and meet the criteria for both disorders. Approximately $85 \%$ of people with depression have a significant anxiety disorder and $90 \%$ of people with anxiety disorders have a depressive disorder[22]. Clinical studies suggest that anxiety not only accompanies symptoms of depression but maybe an expected precursor syndrome in the development of at least some forms of depression. Recent genetic and epidemiological data further suggest that at least some forms of anxiety and depression may be different phenotypic expressions of the same genetic predisposition under different environmental conditions. Animal studies further suggest a causal relationship between anxiety and the development of a behavioral syndrome called "learned helplessness, " an animal model of depression produced by exposing animals to unavoidable stress. Many of the behavioral and physiological features of the syndrome are similar to those observed in patients with depression[44]. Empirical data suggest that depression and anxiety disorders are highly comorbid; for example, $68 \%$ of depressed patients also meet the criteria for comorbid lifetime anxiety disorders[45]. Similarly, $45 \%-46 \%$ of the 3787 outpatients with depression in the STAR*D study were considered to meet the criteria for anxiety depression[19].The study of Näslund et al.[23], illustrates the close relationship between anxiety and depression.

This mixed category should be used if both anxiety and depressive disorders are present, but neither group of symptoms is sufficient to meet the appropriate diagnosis when considered separately. If severe anxiety is accompanied by a lesser degree of depression, other categories of anxiety or phobic disorders should be used. If both depression and anxiety syndromes are present and each is sufficient to meet the corresponding diagnosis, this category should not be used, but rather the diagnosis of both disorders should be recorded. For practical reasons, if only one diagnosis can be made, depression should be given priority. If only worry or excessive worry is present, without vegetative symptoms, this category should not be used. Some vegetative symptoms (tremors, palpitations, dry mouth, stomach-churning sensation) must be present, even if they are intermittently present.

Generalized anxiety disorder, on the other hand, is characterized by generalized and persistent anxiety that is not limited to, or even predominantly seen in, any particular external environment (i.e., "freefloating"). As with other anxiety disorders, the predominant symptoms are highly variable, but the following complaints are common: generalized nervousness, shaking, muscle tension, sweating, lightheadedness, palpitations, dizziness, and epigastric discomfort. Patients often complain that they or a loved one will soon have an illness or disaster on the horizon. This disorder is more common in women and is often associated with stress. The course of the disease is variable but tends to fluctuate and become chronic. 
There is also research support that shows that undergraduates are at higher risk of developing mental health disorders[46]. Compared to seniors, underclassmen are less able to cope with new environments, making them less effective, and their lack of independence and autonomy makes mental health conditions more prevalent among underclassmen. This is also a function of the impact of the new university environment and the stress associated with being away from family and friends.

Subgroup analyses revealed that for females and rural-born subjects, state traits fully and partially mediated the effect between sleep disturbance and depression, whereas, for males and urban-born subjects, state traits fully mediated the effect between sleep disturbance and depression. This may be related to the fact that females are more sensitive to emotional perceptions and that those born in rural areas perceive environmental changes more prominently after attending college. Usually, universities are set up in cities, and the change in the living environment is relatively weak for those who have always lived in cities. It is possible that this makes the effect of state traits more pronounced for females and those born in rural areas. The effect of sleep disturbance on depression was entirely dependent on the change in state traits. This suggests that improving sleep disturbance may prevent depression[39], Simultaneous improvement in the state traits of the study participants of the intervention would largely improve depression outcomes[47].

Studies have shown that women have higher levels of anxiety than men, and epidemiological studies have concluded that women are more likely to experience psychological symptoms than men. This may be due to the fact that women complain more about high course loads, are more likely to ever complain about physical and psychological symptoms, and face fewer employment opportunities than men. In contrast, one study reported that[48], depressive symptoms occur more frequently in men and may be influenced by factors such as anxiety caused by the need to be employed in time to take on family responsibilities, the effects of substance abuse, or pressure from peers. In our survey facing students of Anhui Medical University, the prevalence of depression was detected in $41.40 \%$ (518) of medical students, of which $26.65 \%$ (327), $13.94 \%$ (171), and $0.81 \%$ (10) were mild, moderate, and severe, respectively. In the same survey in foreign medical universities, it was found that in Alexandria University: $57.9 \%$ of medical students suffer from depression. Another study conducted on medical students at the University of Mansoura reported: the prevalence of depression was 28.3\%[49]. Labib et al. of Fayoum University reported that medical students have statistically significantly higher sources of academic and family stress than non-medical students.

Previous studies have shown that perceived stress is a major obstacle to sleep and erodes sleep quality[50]. Specifically, the higher the perceived stress, the worse the quality of sleep[51-55], a reduction in perceived stress is a predictor of better sleep quality. Therefore, in daily life, college students can improve their sleep quality by reducing or transforming the level of perceived stress. At the same time, more mental health lectures and activities based on the school can increase the contact between students and socially relevant[56], land the ability to build stronger, healthier relationships between students, faculty, and counselors[57], School-based programs can reduce anxiety and depression, and both demographics and program characteristics can influence the effectiveness of school-based mental 
health programs[58], Thus, depression can be prevented from occurring. In addition, online sleep education interventions can also improve sleep behavior, sleep quality, and depression scores. Effective online sleep education interventions for college students have significant effects on mood and sleep behaviors[59].

\section{Conclusions And Implications}

Research hypothesis 1 that sleep affects the onset of depression and that people with sleep disorders are more likely to experience depression was supported.

The research hypothesis that 2-state traits play a mediating role in the influence of sleep disorders on depression was supported.

Therefore, it is of great practical importance to pay attention to the relationship between sleep disorders and depressive states trait anxiety, so that we can take appropriate measures to improve the sleep quality of college students and thus reduce depression and anxiety, and promote the physical and mental health of college students.

\section{Abbreviations}

PSQI: Pittsburgh sleep quality index

WT: Anxiety and state-trait worry

S-Al: state anxiety

T-Al: trait anxiety

STAI: State-Trait Anxiety Inventory

SDS: Depression Self-Rating Scale

\section{Declarations}

All methods were carried out in accordance with relevant guidelines and regulations.

\section{Ethics approval and consent to participate}

The Research and Clinical Trials Ethics Committee of the First Affiliated Hospital of Zhengzhou University approved CHARLS, and all participants were required to provide written informed consent. The ethical approval number is: 2021-KY-0669.

\section{Consent for publication}




\section{Availability of data and materials}

All data generated or analysed during this study are included in this published article [and its supplementary information files].

\section{Competing interests}

The authors declare that the research was conducted in the absence of any commercial or financial relationships that could be construed as a potential conflict of interest.

\section{Funding}

This work was supported by the Joint Co-Construction Program of Medical Science and Technology of Henan Province (LHGJ20200347), Key Laboratory of Philosophy and Social Sciences of Colleges and Universities in Guangdong Province: Public Health Policy Research \&Evaluation (2015WSYS0010) and Guangzhou Public Health Service System Construction Research Foundation (2021-2023).

\section{Author Contributions}

Jiangyun Chen: Conceptualization, Writing- Original draft preparation; Yusupujiang Tuersun: Data curation, Writing- Original draft preparation. Jiao Yang: Data curation; Man Xiong: Data curation; Yueying Wang: Data curation; Xinyi Rao: Data curation; Shuai Jiang: Writing - Review \& Editing.

\section{Acknowledgments}

We thank all participants and staffs at the study sites for their cooperation.

\section{References}

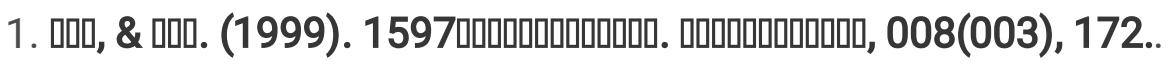

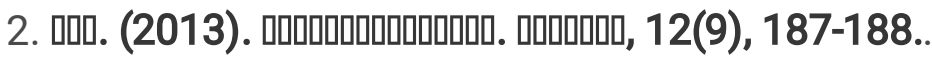

3. Rechtschaffen A, Bergmann BM, Everson CA, Kushida CA, Gilliland MA: Sleep deprivation in the rat: X. Integration and discussion of the findings. SLEEP 1989, 12(1):68-87.

4. Akman T, Yavuzsen T, Sevgen Z, Ellidokuz H, Yilmaz AU: Evaluation of sleep disorders in cancer patients based on Pittsburgh Sleep Quality Index. EUR J CANCER CARE 2015, 24(4):553-559.

5. Yilmaz M: Evaluation of sleep disorders in nonmetastatic breast cancer patients based on pittsburgh sleep quality index. J CANCER RES THER 2020, 16(6):1274-1278. 
6. Akman T, Yavuzsen T, Sevgen Z, Ellidokuz H, Yilmaz AU: Evaluation of sleep disorders in cancer patients based on Pittsburgh Sleep Quality Index. EUR J CANCER CARE 2015, 24(4):553-559.

7. Yilmaz M: Evaluation of sleep disorders in nonmetastatic breast cancer patients based on pittsburgh sleep quality index. J CANCER RES THER 2020, 16(6):1274-1278.

8. Ohayon MM, Roth T: Place of chronic insomnia in the course of depressive and anxiety disorders. $J$ PSYCHIATR RES 2003, 37(1):9-15.

9. Doi Y, Minowa M, Uchiyama M, Okawa M, Kim K, Shibui K, Kamei Y: Psychometric assessment of subjective sleep quality using the Japanese version of the Pittsburgh Sleep Quality Index (PSQI-J) in psychiatric disordered and control subjects. PSYCHIAT RES 2000, 97(2-3):165-172.

10. Wang F, Biro E: Determinants of sleep quality in college students: A literature review. EXPLORE-NY 2021, 17(2):170-177.

11. Y T, L M L: [Epidemiological study of sleep disorder in the elderly]. Zhonghua liu xing bing xue za zhi = Zhonghua liuxingbingxue zazhi 2017, 38(7).

12. Cho HJ, Lavretsky H, Olmstead R, Levin MJ, Oxman MN, Irwin MR: Sleep Disturbance and Depression Recurrence in Community-Dwelling Older Adults: A Prospective Study. AM J PSYCHIAT 2008, 165(12):1543-1550.

13. citation-20386142.

14. Finan $\mathrm{PH}$, Smith MT: The comorbidity of insomnia, chronic pain, and depression: Dopamine as a putative mechanism. SLEEP MED REV 2013, 17(3):173-183.

15. Ekici O: Association of stress, anxiety, and depression levels with sleep quality in patients with temporomandibular disorders. CRANIO-THE JOURNAL OF CRANIOMANDIBULAR \& SLEEP PRACTICE.

16. Dam TL, Ewing S, Ancoli-Israel S, Ensrud K, Redline S, Stone K: Association between sleep and physical function in older men: The osteoporotic fractures in men sleep study. J AM GERIATR SOC 2008, 56(9):1665-1673.

17. Nadorff MR, Nazem S, Fiske A: Insomnia symptoms, nightmares, and suicidal ideation in a college student sample. SLEEP 2011, 34(1):93-98.

18. Gaultney JF: The prevalence of sleep disorders in college students: impact on academic performance. J AM COLL HEALTH 2010, 59(2):91-97.

19. Spoormaker VI, Verbeek I, van den Bout J, Klip EC: Initial validation of the SLEEP-50 questionnaire. BEHAV SLEEP MED 2005, 3(4):227-246.

20. Lund HG, Reider BD, Whiting AB, Prichard JR: Sleep patterns and predictors of disturbed sleep in a large population of college students. J Adolesc Health 2010, 46(2):124-132.

21. Singleton RJ, Wolfson AR: Alcohol consumption, sleep, and academic performance among college students. J STUD ALCOHOL DRUGS 2009, 70(3):355-363.

22. Tiller JW: Depression and anxiety. Med J Aust 2013, 199(S6):S28-S31.

23. Naslund J, Hieronymus F, Emilsson JF, Lisinski A, Nilsson S, Eriksson E: Incidence of early anxiety aggravation in trials of selective serotonin reuptake inhibitors in depression. Acta Psychiatr Scand 
2017, 136(4):343-351.

24. Dugas MJ, Marchand A, Ladouceur R: Further validation of a cognitive-behavioral model of generalized anxiety disorder: diagnostic and symptom specificity. J ANXIETY DISORD 2005, 19(3):329-343.

25. Carney $C E$, Harris AL, Moss TG, Edinger JD: Distinguishing rumination from worry in clinical insomnia. BEHAV RES THER 2010, 48(6):540-546.

26. Strand N, Fang L, Carlson JM: Sex Differences in Anxiety: An Investigation of the Moderating Role of Sex in Performance Monitoring and Attentional Bias to Threat in High Trait Anxious Individuals. FRONT HUM NEUROSCI 2021, 15.

27. Lonigan CJ, Vasey MW, Phillips BM, Hazen RA: Temperament, anxiety, and the processing of threatrelevant stimuli. Journal of clinical child and adolescent psychology: the official journal for the Society of Clinical Child and Adolescent Psychology, American Psychological Association, Division 53 2004, 33(1):8-20.

28. Yan $Y$, Lin R, Tang X, He F, Cai W, Su Y: The relationship between worry tendency and sleep quality in Chinese adolescents and young adults: the mediating role of state-trait anxiety. J HEALTH PSYCHOL 2014, 19(6):778-788.

29. Buysse DJ, Reynolds CR, Monk TH, Berman SR, Kupfer DJ: The Pittsburgh Sleep Quality Index: a new instrument for psychiatric practice and research. Psychiatry Res 1989, 28(2):193-213.

30. Hinz A, Glaesmer H, Braehler E, Loeffler M, Engel C, Enzenbach C, Hegerl U, Sander C: Sleep quality in the general population: psychometric properties of the Pittsburgh Sleep Quality Index, derived from a German community sample of 9284 people. SLEEP MED 2017, 30:57-63.

31. de la Vega R, Tome-Pires C, Sole E, Racine M, Castarlenas E, Jensen MP, Miro J: The Pittsburgh Sleep Quality Index: Validity and factor structure in young people. Psychol Assess 2015, 27(4):e22-e27.

32. Lin CS, Wu SY, Yi CA: Association between Anxiety and Pain in Dental Treatment: A Systematic Review and Meta-analysis. J DENT RES 2017, 96(2):153-162.

33. Sirin Y, Yildirimturk S, Ay N: Do state-trait anxiety and previous unpleasant dental experiences predict the need for sedation in women having third molar surgery? Br J Oral Maxillofac Surg 2020, 58(5):530-534.

34. Schrag A, Barone P, Brown RG, Leentjens AF, McDonald WM, Starkstein S, Weintraub D, Poewe W, Rascol O, Sampaio $\mathrm{C}$ et al: Depression rating scales in Parkinson's disease: critique and recommendations. Mov Disord 2007, 22(8):1077-1092.

35. Jokelainen J, Timonen M, Keinanen-Kiukaanniemi S, Harkonen P, Jurvelin H, Suija K: Validation of the Zung self-rating depression scale (SDS) in older adults. SCAND J PRIM HEALTH 2019, 37(3):353-357.

36. Jegede RO: Psychometric properties of the Self-Rating Depression Scale (SDS). The Journal of psychology 1976, 93(1st Half):27-30.

37. Baron RM, Kenny DA: The moderator-mediator variable distinction in social psychological research: conceptual, strategic, and statistical considerations. J PERS SOC PSYCHOL 1986, 51(6):1173-1182. 
38. Associations between movement behaviors and emotional changes in toddlers and preschoolers during early stages of the COVID-19 pandemic in Chile.

39. Nyer M, Farabaugh A, Fehling K, Soskin D, Holt D, Papakostas GI, Pedrelli P, Fava M, Pisoni A, Vitolo O et al: Relationship between sleep disturbance and depression, anxiety, and functioning in college students. DEPRESS ANXIETY 2013, 30(9):873-880.

40. Pires GN, Bezerra AG, Tufik S, Andersen ML: Effects of acute sleep deprivation on state anxiety levels: a systematic review and meta-analysis. SLEEP MED 2016, 24:109-118.

41. Psychiatry Research.

42. Lopez R, Barateau L, Evangelista E, Dauvilliers Y: Depression and Hypersomnia: A Complex Association. Sleep Medicine Clinics 2017, 12(3):395-405.

43. Wang $X$, Cheng $S, X u H$ : Systematic review and meta-analysis of the relationship between sleep disorders and suicidal behaviour in patients with depression. BMC PSYCHIATRY 2019, 19(1):303.

44. Paul SM: Anxiety and depression: a common neurobiological substrate? J Clin Psychiatry 1988, 49 Suppl:13-16.

45. Kessler RC, Berglund P, Demler O, Jin R, Koretz D, Merikangas KR, Rush AJ, Walters EE, Wang PS: The epidemiology of major depressive disorder: results from the National Comorbidity Survey Replication (NCS-R). JAMA 2003, 289(23):3095-3105.

46. Abdel Wahed WY, Hassan SK: Prevalence and associated factors of stress, anxiety and depression among medical Fayoum University students. Alexandria journal of medicine 2017, 53(1):77-84.

47. Austin MP, Tully L, Parker G: Examining the relationship between antenatal anxiety and postnatal depression. J Affect Disord 2007, 101(1-3):169-174.

48. r w w Click to buy NOW.

49. SELF - REPORTED DEPRESSION AND ANXIETY BY STUDENTS AT AN EGYPTIAN MEDICAL SCHO.

50. Akerstedt T, Orsini N, Petersen H, Axelsson J, Lekander M, Kecklund G: Predicting sleep quality from stress and prior sleep-a study of day-to-day covariation across six weeks. SLEEP MED 2012, 13(6):674-679.

51. Brand S, Beck J, Kalak N, Gerber M, Kirov R, Puhse U, Hatzinger M, Holsboer-Trachsler E: Dream recall and its relationship to sleep, perceived stress, and creativity among adolescents. $J$ Adolesc Health 2011, 49(5):525-531.

52. Brand S, Beck J, Kalak N, Gerber M, Kirov R, Puehse U, Hatzinger M, Holsboer-Trachsler E: Dream Recall and Its Relationship to Sleep, Perceived Stress, and Creativity Among Adolescents. J ADOLESCENT HEALTH 2011, 49(5):525-531.

53. Charles LE, Slaven JE, Mnatsakanova A, Ma C, Violanti JM, Fekedulegn D, Andrew ME, Vila BJ, Burchfiel CM: Association of perceived stress with sleep duration and sleep quality in police officers. Int J Emerg Ment Health 2011, 13(4):229-241.

54. Sadeh A, Keinan G, Daon K: Effects of stress on sleep: the moderating role of coping style. HEALTH PSYCHOL 2004, 23(5):542-545. 
55. Xu Q, Zhao Y, Chen H, Jing J: Exploring Sleep Quality and Related Factors in Chinese Midlife Women. Health Care Women Int 2016, 37(6):620-635.

56. Curran T, Wexler L: School-Based Positive Youth Development: A Systematic Review of the Literature. J Sch Health 2017, 87(1):71-80.

57. Durlak JA, Taylor RD, Kawashima K, Pachan MK, DuPre EP, Celio Cl, Berger SR, Dymnicki AB, Weissberg RP: Effects of positive youth development programs on school, family, and community systems. Am J Community Psychol 2007, 39(3-4):269-286.

58. Feiss R, Dolinger SB, Merritt M, Reiche E, Martin K, Yanes JA, Thomas CM, Pangelinan M: A Systematic Review and Meta-Analysis of School-Based Stress, Anxiety, and Depression Prevention Programs for Adolescents. J Youth Adolesc 2019, 48(9):1668-1685.

59. Hershner S, O'Brien LM: The Impact of a Randomized Sleep Education Intervention for College Students. J CLIN SLEEP MED 2018, 14(03):337-347.

\section{Figures}

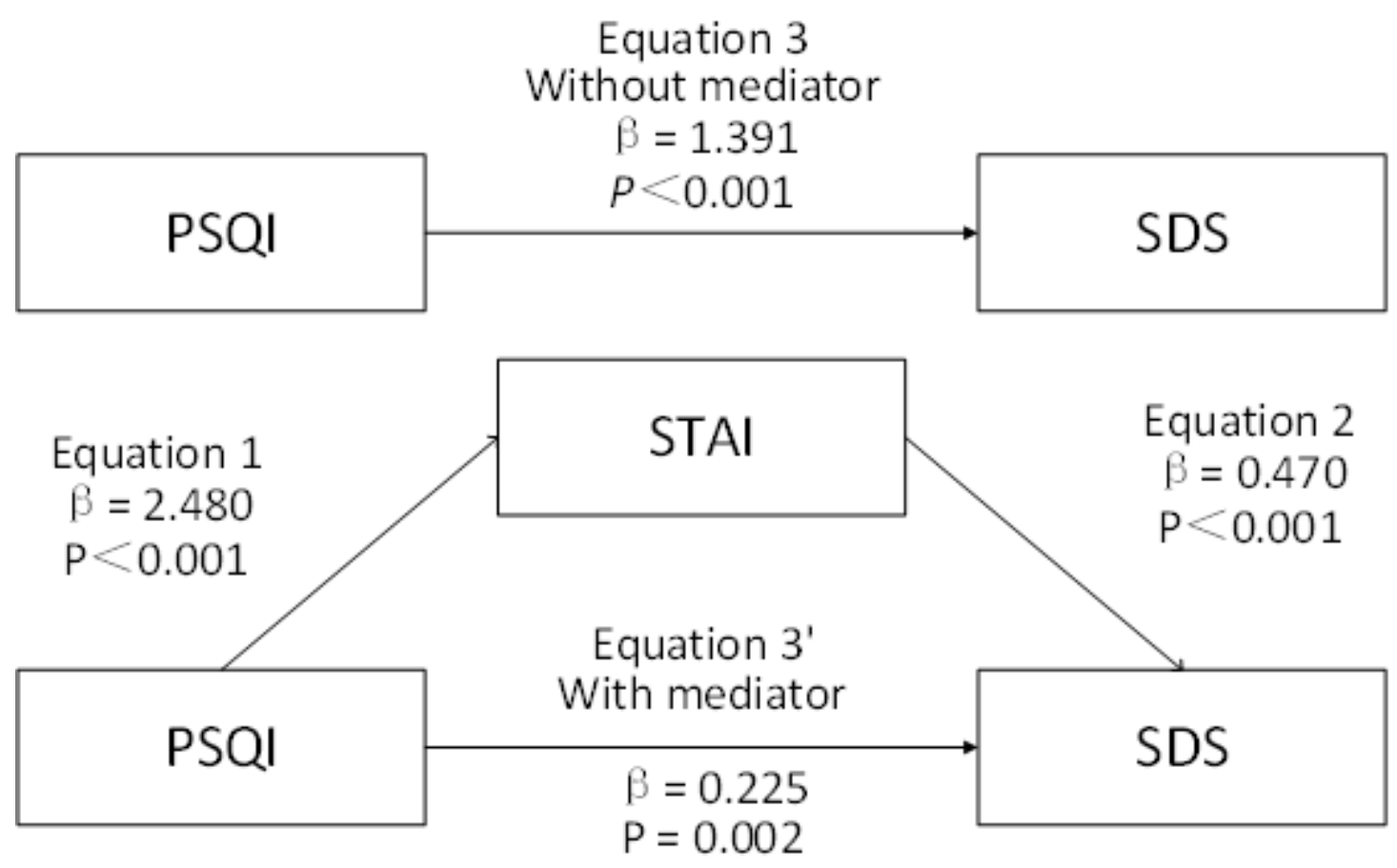

Sobel test: $z=15.090 ; 83.79 \% ; P<0.001$

Figure 1

Mediation Analysis

Note: STAI = State-Trait Anxiety Inventory; PSQI = Pittsburgh Sleep Quality Index; SDS = Self-rating depression scale. The Sobel test was used to test the hypothesis that the indirect role was equal to 0 , 
adjusting for potential confounders (gender, birthplace, grade, major, race, only child, close relationship, education of close relationship, education of father, education of mother, job of close relationship, job of father, job of mother). Values are bolded if they achieved statistical significance at $p \leq .05$.

\section{Supplementary Files}

This is a list of supplementary files associated with this preprint. Click to download.

- SupplementaryTable.docx 